\title{
Adhesion of Campylobacter jejuni Is Increased in Association with Foodborne Bacteria
}

\author{
Anja Klančnik ${ }^{1, *(\mathbb{D}}$, Ivana Gobin ${ }^{2}\left(\mathbb{D}\right.$, Barbara Jeršek ${ }^{1}\left(\mathbb{D}\right.$, Sonja Smole Možina ${ }^{1}{ }^{1}$, \\ Darinka Vučković $^{2}$ D, Magda Tušek Žnidarič ${ }^{3}$ and Maja Abram ${ }^{2,4}$ \\ 1 Department of Food Science and Technology, Biotechnical Faculty, University of Ljubljana, Jamnikarjeva 101, \\ SI-1000 Ljubljana, Slovenia; barbka.jersek@bf.uni-lj.si (B.J.); Sonja.Smole@bf.uni-lj.si (S.S.M.) \\ 2 Department of Microbiology, Faculty of Medicine, University of Rijeka, Braće Branchetta 20/1, \\ HR-51000 Rijeka, Croatia; ivanagobin@yahoo.co.uk (I.G.); darinka.vuckovic@medri.uniri.hr (D.V.); \\ maja.abram@medri.uniri.hr (M.A.) \\ 3 Department of Biotechnology and Systems Biology, National Institute of Biology, Večna pot 111, \\ SI-1000 Ljubljana, Slovenia; Magda.Tusek.Znidaric@nib.si \\ 4 Department of Clinical Microbiology, Clinical Hospital Centre Rijeka, Krešimirova 42, \\ HR-51000 Rijeka, Croatia \\ * Correspondence: anja.klancnik@bf.uni-lj.si; Tel.: +386-1-3203-762
}

Received: 14 January 2020; Accepted: 30 January 2020; Published: 31 January 2020

\begin{abstract}
The aim of this study was to evaluate Campylobacter jejuni NTCT 11168 adhesion to abiotic and biotic surfaces when grown in co-culture with Escherichia coli ATCC 11229 and/or Listeria monocytogenes $4 \mathrm{~b}$. Adhesion of $C$. jejuni to polystyrene and to Caco-2 cells and Acanthamoeba castellanii was lower for at least $3 \log \mathrm{CFU} / \mathrm{mL}$ compared to E. coli and L. monocytogenes. Electron micrographs of ultrathin sections revealed interactions of $C$. jejuni with host cells. In co-culture with E. coli and L. monocytogenes, adhesion of $C$. jejuni to all tested surfaces was significantly increased for more than $1 \log \mathrm{CFU} / \mathrm{mL}$. There was 10\% higher aggregation for C. jejuni than for other pathogens, and high co-aggregation of co-cultures of C. jejuni with E. coli and L. monocytogenes. These data show that C. jejuni in co-cultures with E. coli and L. monocytogenes present significantly higher risk than C. jejuni as mono-cultures, which need to be taken into account in risk evaluation. C. jejuni adhesion is a prerequisite for their colonization, biofilm formation, and further contamination of the environment. C. jejuni survival under adverse conditions as a factor in their pathogenicity and depends on their adhesion to different surfaces, not only as individual strains, but also in co-cultures with other bacteria like E. coli and L. monocytogenes.
\end{abstract}

Keywords: adhesion; abiotic/biotic surface; Campylobacter jejuni; co-culture; survival; pathogenicity

\section{Introduction}

According to the World Health Organisation, the incidence and prevalence of campylobacteriosis is still increasing in both developed and developing countries, which is mainly associated with the consumption of undercooked poultry meat products, and with outbreaks arising from contaminated water [1]. The attachment of Campylobacter jejuni to materials used as industrial surfaces is an important step for bacterial adaptation, high frequency of resistance, and induced stress response mechanisms. This promotes survival and persistence of $C$. jejuni in the food chain, and can lead to cross-contamination and transmission to a subsequent host [1-4].

It is known that $C$. jejuni can adhere to different inert surfaces (e.g., stainless steel, glass fibre, beads and coverslips, nitrocellulose membranes, various plastics) [2,3,5,6] and living surfaces (e.g., animal and human intestinal cell lines) [5-10]. Cell adhesion to these surfaces is followed by biofilm formation, as an advanced protection mechanism against environmental stresses, antimicrobial agents, and 
the host immune system. Campylobacter adhesion thus contributes to the biofilms or biofouling formations that provide protected modes for bacterial growth and allow bacterial survival in hostile environments, whereby their physiology and behaviour are significantly different from their planktonic counterparts $[1,3,11]$.

Adhesion of Campylobacter to epithelial cells represents a very important virulence property in human/ animal infections, and this is crucial not only for Campylobacter survival out of a host, but also during host-pathogen interactions, invasion of the intracellular space, and crossing of host barriers, and, thus, for the survival of these bacteria [12]. Contamination by multiple pathogen bacteria, including Escherichia coli and Listeria monocytogenes, may cause symptoms that are more complex and serious than those caused by infection by only one pathogen [13]. Additionally, to survive environmental stresses, the Campylobacters response mechanisms include cell adhesion and invasion, and intracellular survival in protozoa present in water systems, which are also vectors for Campylobacter transmission and human infection [12]. C. jejuni can thus attach to and survive within free-living protozoa [12,14], which can also occur in the same food-related environments [15]. While harbouring bacteria, free-living protozoa simultaneously serve as their shelter, reservoir, and vector in the environment [16]. However, in addition to protozoa, C. jejuni encounter a variety of different bacteria in the environmental niches that they share, with which they inevitably interact. Indeed, today it is widely accepted that multi-species biofilms are the main forms of microbial existence in nature. The development, structure, and function of such polymicrobial communities will depend on the synergistic and antagonistic relationships between the different species [17].

Thus, adhesion of $C$. jejuni to different surfaces and to other microorganisms has a crucial role in their survival and persistence in the food production chain [1-4], as well as in their pathogenicity and virulence $[1,9,18-20]$.

However, the precise molecular mechanisms involved in the multifactorial event of adhesion to abiotic/ biotic surfaces have not been adequately investigated to date. The main cell properties involved in this adhesion include morphology, membranes, membrane proteins, host proteins, fatty acid metabolism, intracellular transport, chaperones, motility, hydrophobicity, quorum-sensing, chemotaxis, aggregation, stress responses, and extracellular polymeric matrix formation. The further external factors involved in cell adhesion include the material surface characteristics and physicochemical factors, and the environmental conditions $[2,17,18,20]$. The $C$. jejuni binding mechanisms to biotic surfaces generally involve very specific sub-molecular interactions, many of which are not well understood and are strain dependent, such as transmission, capsule production, hydrated extracellular polymeric substances, protein glycosylation, adhesion, epithelial cell invasion, and intestinal colonization and infection $[2,3,9,11]$.

The aim of the present study was to investigate C. jejuni adhesion in co-cultures with E. coli and L. monocytogenes to an abiotic polystyrene surface and to the biotic surfaces of human intestinal epithelial Caco-2 cells and Acanthamoeba castellanii amoebae. L. monocytogenes and E. coli were chosen as Gram-positive and Gram-negative food-borne bacteria, respectively, that might have different effects on $C$. jejuni adhesion in co-cultures. The further studies here focused on $C$. jejuni aggregation properties and visualisation of $C$. jejuni interactions with Caco-2 cells and A. castellanii.

\section{Materials and Methods}

\subsection{Bacterial Strains and Growth Conditions}

Campylobacter jejuni NTCT 11168, Escherichia coli ATCC 11229, and Listeria monocytogenes (4b, Institute for Hygiene and Microbiology, Wuerzburg, Germany) were used from the culture collection of the Laboratory for Food Microbiology at the Department of Food Science and Technology, Biotechnical Faculty, University of Ljubljana (Ljubljana, Slovenia). E. coli and L. monocytogenes were grown aerobically in $5 \mathrm{~mL}$ Mueller-Hinton broth (MHB; Oxoid, Basingstoke, UK) at $37^{\circ} \mathrm{C}$ for $20 \mathrm{~h}$, with continuous 
shaking at $75 \mathrm{rpm}$. C. jejuni were grown under microaerophilic conditions $\left(5 \% \mathrm{O}_{2}, 10 \% \mathrm{CO}_{2}, 85 \% \mathrm{~N}_{2}\right)$ in $5 \mathrm{~mL}$ MHB with $5 \%$ horse blood (Oxoid Basingstoke, UK), at $42{ }^{\circ} \mathrm{C}$ for $20 \mathrm{~h}$.

Bacterial numbers were determined by spectrophotometric measurements of absorbance at 600 $\mathrm{nm}$, and the inocula were prepared in $\mathrm{MHB}$ at $10^{8} \mathrm{CFU} / \mathrm{mL}$ of each bacterium. For bacterial counting in mono-culture experiments, C. jejuni, E. coli, and L. monocytogenes were plated on Mueller-Hinton agar (MHA; Oxoid, Basingstoke, UK) plates and incubated under the appropriate conditions (as described above), with the colonies counted and expressed as numbers of bacteria $(\mathrm{CFU} / \mathrm{mL})$. For the co-cultures, bacterial cocktails were prepared from 20-h mono-cultures of C. jejuni, E. coli, and L. monocytogenes, mixed in the ratio 1:1:1. For bacterial counting in the co-cultures, the bacterial cocktails were plated on selective agar, as follows: For C. jejuni, Campylobacter blood-free-medium base (Karmali, CM739; Oxoid) and Campylobacter selective supplement (SR0167E; Oxoid); for E. coli, Tryptone Bile Agar with X-glucuronide (TBX, 5121562; Biolife) plates; for L. monocytogenes, Agar Listeria Ottavani \& Agosti (ALOA, 4016052; Biolife, Milan, Italy) plates with ALOA selective supplement (42501; Biolife). The plates were incubated under the appropriate conditions (as described above) and the colonies were counted and expressed as numbers of bacteria $(\mathrm{CFU} / \mathrm{mL})$.

\subsection{Caco-2 Cell Culture Conditions}

Caco-2 human intestinal cells were grown in Dulbecco's minimum essential medium (DMEM; Lonza Group Ltd. Verviers, Verviers, Belgium) supplemented with 10\% foetal bovine serum (FBS; Capricorn Scientific GmbH, Ebsdorfergrund, Germany), 2 mM L-glutamine (Lonza Group Ltd. Verviers), 10,000 U/mL penicillin (Lonza Group Ltd. Verviers), and 10,000 mg/mL streptomycin (Lonza Group Ltd. Verviers). The cells were grown routinely in tissue culture flasks (TPP, Trasadingen, Switzerland) at $37^{\circ} \mathrm{C}$ in a $5 \% \mathrm{CO}_{2}$ humidified atmosphere. Cell counts were determined using a Neubauer cell counting chamber (Roth). Confluent cells were harvested by trypsinisation in $0.01 \%$ ethylenediaminetetraacetic acid (EDTA, Sigma-Aldrich Chemie GmbH, Taufkirchen, Germany) and maintained in 25- $\mathrm{cm}^{2}$ culture flasks (TPP, Trasadingen). Polarized Caco-2 cell monolayers were used after 10 to 14 days of growth.

\subsection{Acanthamoeba castellanii Growth Conditions}

Acanthamoeba castellanii ATCC 30234 were maintained axenically in $25-\mathrm{cm}^{2}$ culture flasks (TPP, Trasadingen, Switzerland) with peptone-yeast extract glucose medium (PYG 712 medium: $20 \mathrm{~g} / \mathrm{L}$ proteose peptone (Oxoid Basingstoke, $\mathrm{UK}$ ); $1 \mathrm{~g} / \mathrm{L}$ yeast extract (Oxoid Basingstoke, $\mathrm{UK}$ ); $18 \mathrm{~g} / \mathrm{L}$ glucose; $1 \mathrm{~g} / \mathrm{L}$ sodium citrate $2 \mathrm{H}_{2} \mathrm{O} ; 9.8 \mathrm{~g} / \mathrm{L} \mathrm{MgSO} 4 \cdot 7 \mathrm{H}_{2} \mathrm{O} ; 4.4 \mathrm{~g} / \mathrm{L} \mathrm{Na}_{2} \mathrm{HPO}_{4} \cdot 12 \mathrm{H}_{2} \mathrm{O} ; 3.4 \mathrm{~g} / \mathrm{L} \mathrm{KH}_{2} \mathrm{PO}_{4}, 0.2 \mathrm{~g} / \mathrm{L}$ $\mathrm{Fe}\left(\mathrm{NH}_{4}\right) 2\left(\mathrm{SO}_{4}\right)_{2} \cdot 6 \mathrm{H}_{2} \mathrm{O}$ (Kemika, Croatia) at $25^{\circ} \mathrm{C}$. The A. castellanii cells were transferred into fresh medium once a week. Cell counts were determined using a Neubauer cell-counting chamber (Roth, Karlsruhe, Germany).

\subsection{Adhesion Assays}

The adhesion of C. jejuni, E. coli, and L. monocytogenes was assessed as mono-cultures and co-cultures.

\subsubsection{Adhesion of Bacteria to Polystyrene}

For bacterial adhesion to polystyrene, 96-well polystyrene microtitre plates (Nunc 266120 polystyrene plates, non-treated sterile with lid, clear flat bottom, $300 \mu \mathrm{L}$ per well; Nunc, Denmark) were inoculated with $200 \mu \mathrm{L}$ bacterial inoculum of C. jejuni, E. coli, and L. monocytogenes as mono-cultures and co-cultures. Control wells were prepared by addition of only MHB. After $24 \mathrm{~h}$ incubation, the supernatants containing the non-adhered cells were removed from each well, and the plates were rinsed three times with sterile Ringer solution (Kemika, Zagreb, Croatia). Finally, $200 \mu$ l Ringer solution was added to each well, followed by sonication at room temperature for $5 \min (28 \mathrm{kHz} ; 300 \mathrm{~W}$; IskraPio, Šentjernej, Slovenia) [5]. For counting of C. jejuni, E. coli, and L. monocytogenes in mono-cultures, each of these bacteria were plated on non-selective MHA plates to determine CFU/mL. For bacterial counting in co-culture experiments, the cocktails of C. jejuni, E. coli and L. monocytogenes were plated on Karmali, 
TBX and ALOA selective plates. After incubation of the plates under the appropriate conditions (as described above), the colonies were counted and expressed as mean numbers of adhered bacteria (CFU/mL).

\subsubsection{Adhesion of Bacteria to Caco-2 Cells}

For bacterial adhesion to Caco-2 cells, these cells were seeded into 24-well tissue culture trays (TPP, Trasadingen) at $10^{5}$ cells per well for $18 \mathrm{~h}$ as previously described [21]. Then, the DMEM supplemented with $10 \%$ FBS, $2 \mathrm{mM}$ L-glutamine, 10,000 U/mL penicillin, and 10,000 $\mathrm{mg} / \mathrm{mL}$ streptomycin was replaced, and the attached cells were washed twice with DMEM supplemented with $10 \%$ FBS, without antibiotics. After $30 \mathrm{~min}$, the bacterial inocula with $10^{8} \mathrm{CFU} / \mathrm{mL}$ C. jejuni, E. coli, and L. monocytogenes as mono-cultures or co-cultures were added. The multiplicity of infection (MOI) obtained was 1000:1 (bacteria: Caco-2 cells). The plates were centrifuged at $170 \times g$ for $5 \mathrm{~min}$, followed by incubation at $37^{\circ} \mathrm{C}$ for $2 \mathrm{~h}$. At the end of this incubation, the monolayers were washed twice with DMEM supplemented with $10 \%$ FBS without antibiotics, to remove the unbound bacteria. The monolayers were then lysed by the addition of $1 \mathrm{~mL} 1.0 \%$ Triton X-100 (Sigma Aldrich Chemie GmbH, Steinheim, Germany) and sonicated at room temperature for $1 \mathrm{~min}(40 \mathrm{kHz}, 200 \mathrm{~W}$; Bacto Sonic Bandelin, Berlin, Germany). The intracellular and adhered bacteria released were counted using MHA plates, and were expressed as the total numbers of bacteria. The differences between the total numbers of bacteria and the numbers of intracellular bacteria were calculated to obtain the numbers of adherent bacterial cells. For the measurements of intracellular bacteria, DMEM supplemented with $10 \%$ FBS containing $100 \mu \mathrm{g} / \mathrm{mL}$ gentamicin was added for $1 \mathrm{~h}$, to kill the extracellular bacteria. Then the antibiotic was removed by washing twice with tissue culture medium, and the cells were lysed with the addition of $1 \mathrm{~mL} 1.0 \%$ Triton X-100, with sonication at room temperature for $1 \mathrm{~min}(40 \mathrm{kHz}, 200 \mathrm{~W})$. The intracellular bacteria released were counted on MHA plates, and are expressed as mean numbers of intracellular bacteria $(\mathrm{CFU} / \mathrm{mL})$. For the counting of C. jejuni, E. coli, and L. monocytogenes, the procedures were the same as described in the section below: Adhesion of bacteria to A. castellanii.

\subsubsection{Adhesion of Bacteria to A. castellanii}

For bacterial adhesion to A. castellanii, the A. castellanii were seeded in PYG 712 medium in 24-well tissue culture trays (TPP, Trasadingen) at $10^{5}$ cells per well and left at $25^{\circ} \mathrm{C}$ for $2 \mathrm{~h}$, as previously described [22]. Then, the medium was replaced and the attached $A$. castellanii cells were washed twice with Page's Amoeba Saline (PAS; $0.12 \mathrm{~g} / \mathrm{L} \mathrm{NaCl}, 2.5 \mathrm{mg} / \mathrm{L} \mathrm{MgSO}{ }_{4} \cdot 2 \mathrm{H}_{2} \mathrm{O}, 45 \mathrm{mg} / \mathrm{L} \mathrm{CaCl} 2 \cdot 2 \mathrm{H}_{2} \mathrm{O}$, $3585 \mathrm{mg} / \mathrm{L} \mathrm{Na} 2 \mathrm{HPO}_{4} \cdot 12 \mathrm{H}_{2} \mathrm{O}, 1365 \mathrm{mg} / \mathrm{L} \mathrm{KH}_{2} \mathrm{PO}_{4}$; Kemika, Croatia). After $30 \mathrm{~min}$, the bacterial inoculum with $10^{8} \mathrm{CFU} / \mathrm{mL}$ C. jejuni, E. coli, and L. monocytogenes as mono-cultures or as co-cultures were added. The multiplicity of infection (MOI) obtained was 1000:1 (bacteria:A. castellanii). The plates were centrifuged at $170 \times g$ for $5 \mathrm{~min}$, and then incubated at $25^{\circ} \mathrm{C}$ for $2 \mathrm{~h}$. After the incubation, the non-adherent bacteria were removed by washing the wells twice with PAS.

The differences between the total numbers of bacteria and the numbers of intracellular bacteria were calculated to obtain the number of adherent bacterial cells on the A. castellanii amoebae surface. For determination of the number of intracellular bacteria, the A. castellanii cells (from 3 wells) were re-suspended in $1 \mathrm{~mL}$ PAS containing $100 \mu \mathrm{g} / \mathrm{mL}$ gentamicin (Sigma-Aldrich Chemie GmbH, Taufkirchen, Germany) and incubated at room temperature for $1 \mathrm{~h}$. The cell monolayers were then washed twice with PAS, and $1 \mathrm{~mL}$ PAS containing 0.3\% Triton X-100 (Sigma Aldrich Chemie GmbH, Taufkirchen, Germany) was added, and sonicated for $1 \mathrm{~min}$ at room temperature (40 kHz, $200 \mathrm{~W}$; Bacto Sonic Bandelin, Germany), to lyse the amoebae. These samples were plated on MHA plates when mono-cultures were used, and on Karmali, TBX, and ALOA plates when co-cultures were used. After incubation $\left(37^{\circ} \mathrm{C}, 24-48 \mathrm{~h}\right.$ in the appropriate atmosphere), the data were expressed as mean numbers of intracellular bacteria $(\mathrm{CFU} / \mathrm{mL})$. The total numbers of (adherent and intracellular) bacteria were determined in the same way as the numbers of intracellular bacteria, obtained without gentamicin treatment. 


\subsection{Aggregation and Co-Aggregation Assays}

The aggregation and co-aggregation assays were performed according to Kos et al. with some modifications. C. jejuni, E. coli, and L. monocytogenes were grown on agar plates, on Karmali Campylobacter agar, TBX and ALOA, respectively [23]. The bacterial cells were harvested and washed twice with sterile phosphate-buffered saline (Oxoid, Basingstoke, UK), with centrifugation at $1075 \times g$ for $5 \mathrm{~min}$. The pellets were resuspended in phosphate-buffered saline, and the optical densities $\left(\mathrm{OD}_{600}\right)$ of the bacterial suspensions were determined using a microplate reader (Tecan Group AG, Männedorf, Switzerland). The bacterial suspensions were then readjusted with sterile phosphate-buffered saline to an $\mathrm{OD}_{600}$ of 1 (C. jejuni: about $0.5 \times 10^{9} \mathrm{CFU} / \mathrm{mL}$; E. coli and L. monocytogenes: $1 \times 10^{9} \mathrm{CFU} / \mathrm{mL}$ ).

Bacterial suspensions for aggregation assays were divided into glass test-tubes $(4 \mathrm{~mL})$ and mixed by vortexing. The $\mathrm{OD}_{600}$ of the carefully pipetted supernatants (upper layers) were measured immediately $(0 \mathrm{~h})$, and then after $2 \mathrm{~h}$ and $24 \mathrm{~h}$ of incubation at room temperature. The aggregation percentages were determined according to Equation (1).

$$
\% \text { aggregation }=\left(1-\frac{O D_{\text {Time }}}{O D_{T 0}}\right) \times 100
$$

where $O D_{\text {Time }}$ is the $O D_{600}$ at the specified times $(2 \mathrm{~h}, 24 \mathrm{~h})$, with $O D_{T 0}$ at time zero $(\mathrm{t}=0 \mathrm{~h})$.

Bacterial suspensions for the co-aggregation assays were prepared in the same way as for the aggregation assays. Equal volumes $(2 \mathrm{~mL})$ of each bacterial suspension were mixed with the other bacterial suspensions, as required (i.e., C. jejuni plus E. coli; C. jejuni plus L. monocytogenes; E. coli plus L. monocytogenes) in glass test-tubes. The $\mathrm{OD}_{600}$ of the carefully pipetted supernatants (upper layers) were measured immediately $(0 \mathrm{~h})$, and after $2 \mathrm{~h}$ and $24 \mathrm{~h}$. The co-aggregation percentages were determined using Equation (2).

$$
\% \text { co-aggregation }=\left[1-\frac{O D_{M i x}}{\frac{O D_{B a c 1}+O D_{B a c 2}}{2}}\right] \times 100
$$

where $O D_{M i x}$ is the $O D_{600}$ of the co-cultures (as indicated above) and $O D_{B a c}$ is the $O D_{600}$ of the bacterial mono-cultures (i.e., C. jejuni, E. coli, L. monocytogenes) at the specified times ( $2 \mathrm{~h}, 24 \mathrm{~h})$.

\subsection{Transmission Electron Microscopy}

Campylobacter jejuni cells adhered to Caco-2 cells and A. castellanii were examined using transmission electron microscopy (TEM). Caco-2 cells and A. castellanii were grown in 24-well tissue culture trays, and the C. jejuni, E. coli and L. monocytogenes as mono-cultures or as co-cultures were added as described above (Adhesion assays), and incubated for $2 \mathrm{~h}$. After this incubation, the non-adherent bacteria were removed by washing twice with DMEM (Caco-2 cells) and with PAS ( $A$. castellanii), and the cells were immediately fixed with $2.5 \%$ glutaraldehyde (SPI, West Chester, PA, USA) in $0.1 \mathrm{M}$ phosphate buffer. The fixed cells were scraped, post-fixed with $1 \% \mathrm{OsO}_{4}$ (SPI, West Chester, PA, USA), and embedded in Agar 100 resin (Agar Scientific, London, UK). Ultrathin sections were stained with $1 \%$ water solution of uranyl acetate (SPI, West Chester, PA, USA) and lead citrate (SPI, West Chester, PA, USA).

The aggregated and co-aggregated samples were visualized using TEM. These were prepared with the negative staining method reported previously [7]. Grids were examined using an electron microscope (Philips CM 100; Philips Electronics N.V. Eindhoven, The Netherlands), which was operated at $80 \mathrm{kV}$. The images were recorded with a CCD camera (Bioscan) or a digital camera (Orius SC 200) using the Digital Micrograph Software (Gatan Inc., Washington, DC, USA). 


\subsection{Statistical Analysis}

The statistical analysis was performed using SPSS Statistics version 20 (IBM Corp., Armonk, NY, USA). The data for the adhesion properties are presented as the number of bacteria $(\mathrm{CFU} / \mathrm{mL})$ and the data for aggregation are presented as percentages of aggregation and co-aggregation. The significances of the differences between the different bacteria as mono-cultures and co-cultures were determined using one-way analysis of variance (ANOVA), and are considered significant at $p<0.05$. All of the experiments were carried out in at least three replicas.

\section{Results}

\subsection{Adhesion}

For the adhesion of $C$. jejuni, polystyrene was used as the abiotic surface, and Caco- 2 cells and A. castellanii as the biotic surfaces. Adhesion to polystyrene (Figure 1) was determined after $24 \mathrm{~h}$, as reported previously [11], and to Caco-2 cells and A. castellanii after $2 \mathrm{~h}$, to avoid the main bacterial internalisation and the formation of amoebal cysts [24]. The numbers of intracellular bacteria were monitored for the Caco-2 cells and A. castellanii, and these levels were taken into account when calculating the numbers of adhered cells. In the $2 \mathrm{~h}$ of incubation, the numbers of intracellular bacteria were low, with $>99 \%$ of the C. jejuni, E. coli, and L. monocytogenes attached to the Caco-2 cells and to $A$. castellanii (data not shown).

The level of adhesion of $C$. jejuni to polystyrene was $4.28 \pm 0.38 \log C F U / m L$, while this was lower for both of the biotic surfaces, as $3.40 \pm 0.11 \log$ CFU $/ \mathrm{mL}$ and $3.31 \pm 0.10 \log \mathrm{CFU} / \mathrm{mL}$ for the $C$. jejuni cells adhered to the Caco-2 cells and A. castellanii, respectively (Figure 1). On the other hand, the adhesion levels of E. coli and L. monocytogenes were comparable, and were significantly greater than for C. jejuni, from $7.22 \pm 0.02 \log \mathrm{CFU} / \mathrm{mL}$ to $8.21 \pm 0.18 \log \mathrm{CFU} / \mathrm{mL}$ across the three surfaces tested (i.e., polystyrene, Caco-2 cells, amoeba cells). When in co-culture with E. coli and L. monocytogenes, the levels of adhered C. jejuni cells were significantly increased by up to $2 \log \mathrm{CFU} / \mathrm{mL}$ in comparison to the C. jejuni mono-cultures, and this was not dependent on the type of surface (Figure 1).
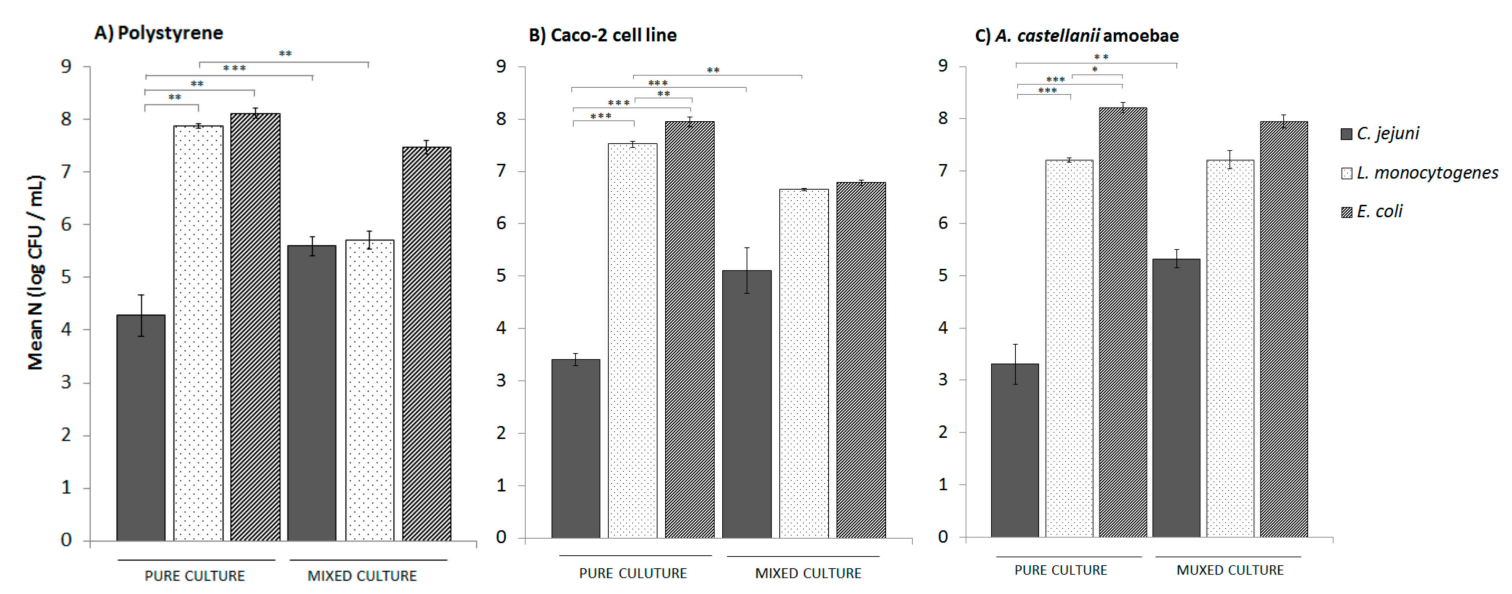

Figure 1. Adhesion of C. jejuni, E. coli, and L. monocytogenes as mono-cultures and as mixed co-cultures of all three of these bacteria to polystyrene, co-incubation for $24 \mathrm{~h} \mathrm{(A);} \mathrm{Caco-2} \mathrm{cells,} \mathrm{co-incubation} \mathrm{for} 2$ $\mathrm{h}$ (B); and A. castellanii amoebae, co-incubation for $2 \mathrm{~h}(\mathrm{C})$. Data are expressed as means \pm standard deviation. ${ }^{*}, p<0.05 ;{ }^{* *}, p<0.01 ;{ }^{* * *}, p<0.001$; as indicated.

In contrast, the levels of E. coli and L. monocytogenes cells in co-cultures that were adhered to polystyrene and Caco-2 cells were 0.5 to $2.5 \log \mathrm{CFU} / \mathrm{mL}$ lower than when they were in mono-cultures. There were no significant differences in the adhesion of E. coli and L. monocytogenes to A. castellanii as mono-cultures and as co-cultures. 
The C. jejuni that adhered to Caco-2 cells and A. castellani were examined using TEM. This showed that after $2 \mathrm{~h}$ of co-cultivation, C. jejuni cells were attached to the surfaces of Caco-2 cells (Figure 2A) and A. castellani (Figure 2D). Closer examination of the TEM micrographs revealed the interactions of $C$. jejuni with the host cells. The Caco-2 cells in the monolayers were tightly connected through many cell-to-cell junctions (Figure 2B, white arrow). Extensions on the surface of the Caco-2 cells (Figure 2C, black arrow) indicated the beginnings of the adhesion of $C$. jejuni. When contact between these bacteria and the cell surface was established, electron dense inclusions appeared just below the plasma membranes of the Caco-2 cells (Figure 2A, white arrowheads). Similar to this projection on the Caco-2 cells, bulges formed on the surface of the A. castellanii (Figure 2F, black arrowheads). Actin microfilaments in Acanthamoeba are located and most concentrated just beneath the plasma membrane and are responsible for cytoplasmic protrusions $[14,15]$. This formation of bulges (Figure 2F) thus appeared to be part of the C. jejuni-A. castellanii interactions that led to adhesion. Occasionally, the interactions between the bacteria and the cell surface were seen as tiny filamentous structures (Figure 2F, black arrow). As these C. jejuni interactions with the Caco-2 cells and Acanthamoeba are very complex, further studies of $C$. jejuni in co-cultures with other bacteria are necessary.
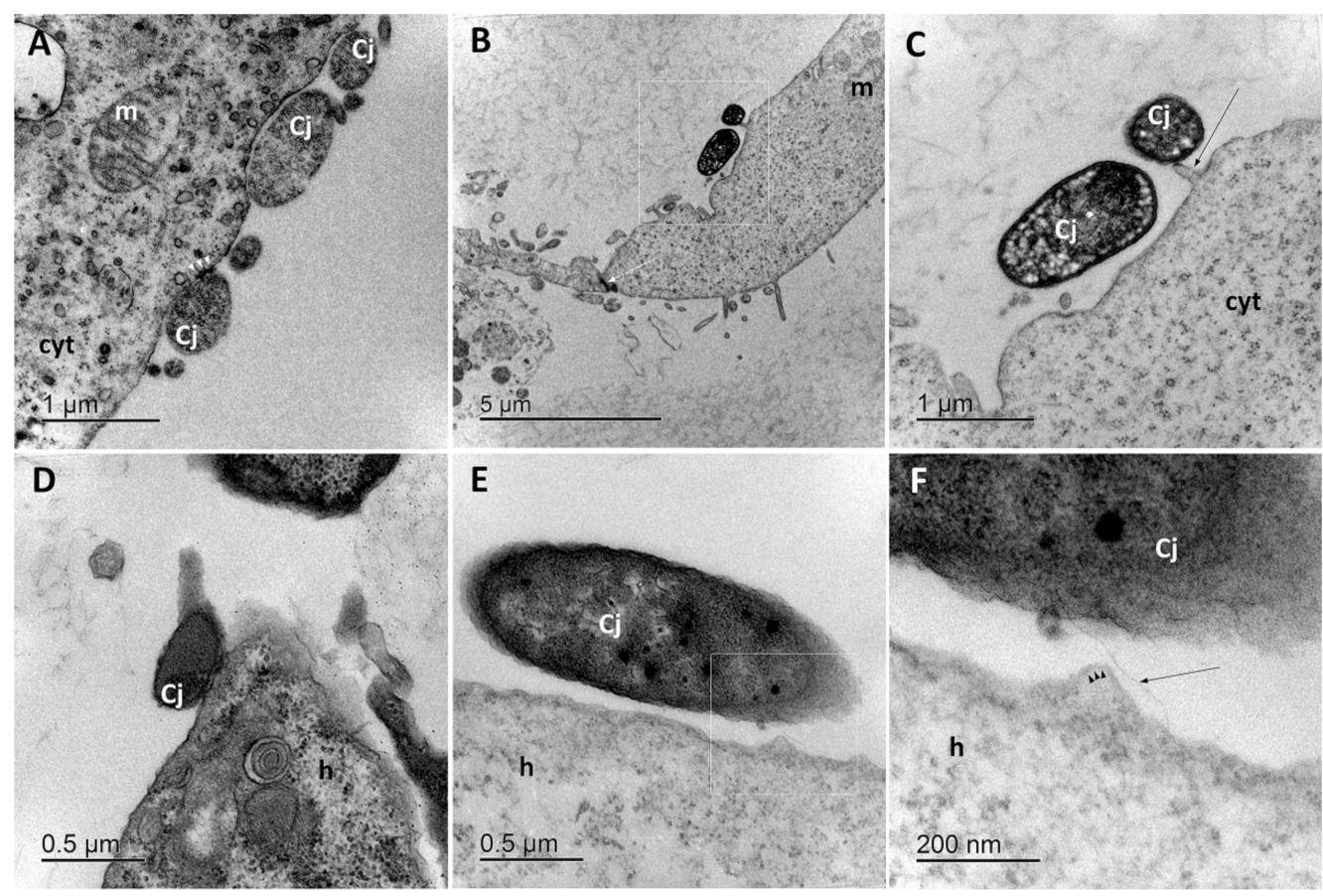

Figure 2. Representative transmission electron micrographs of $C$. jejuni cells adhered to biotic surfaces. (A-C) Adhesion to Caco-2 cells, with enlargement of the box in (B) shown in (C). (D-F) Adhesion to A. castellanii, with enlargement of the box in (D) shown in (F). Cj, Campylobacter jejuni; $\mathrm{m}$, mitochondrion; cyt, cytoplasm of Caco-2 cell; h, hyaloplasm of A. castellanii. Scale bars, as shown.

\subsection{Aggregation}

The aggregation of individual C. jejuni, E. coli and L. monocytogenes cells and their co-aggregation were evaluated after $2 \mathrm{~h}$ and $24 \mathrm{~h}$. The aggregation of all of the bacteria tested was $<7 \%$ in the first 2 h (results not shown), but increased significantly after $24 \mathrm{~h}$, up to $40.1 \% \pm 1.4 \%$ for C. jejuni, $21.5 \%$ $\pm 3.8 \%$ for E. coli, and $26.6 \% \pm 1.5 \%$ for L. monocytogenes (Figure 3 ). The co-aggregation of the mixed C. jejuni, E. coli, and L. monocytogenes was $69.9 \%$, which showed enhanced aggregation of all three bacteria (C. jejuni, 47.1\%; E. coli, 51.8\%; L. monocytogenes, 51.9\%), in comparison to the individual cultures. 


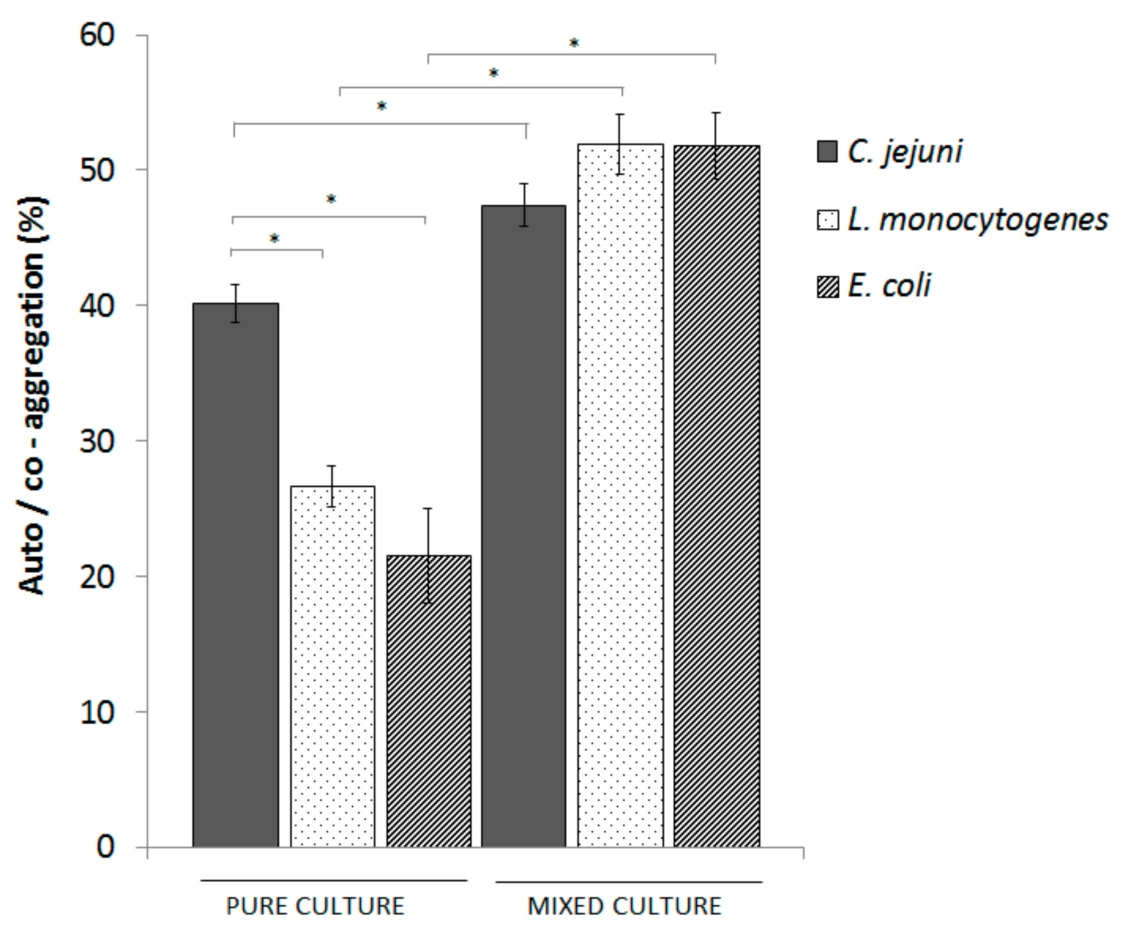

Figure 3. Aggregation and co-aggregation of C. jejuni, E. coli, and L. monocytogenes as mono-cultures and mixed co-culture of the three bacteria after $24 \mathrm{~h}$. Data are means \pm standard deviations. ${ }^{*}, p<0.001$; as indicated.

Representative transmission electron micrographs (TEM) in Figure 4 show the morphology of control C. jejuni, E. coli, and L. monocytogenes planktonic cells. Aggregates of C. jejuni, E. coli, and L. monocytogenes are shown in Figure 5A-C, where these TEM micrographs show the elongated C. jejuni cells (Figure 5A), the short coccoid bacilli shape of E. coli cells that were more closely packed than for C. jejuni (Figure 5B), and the mono or diplo-bacilli of L. monocytogenes (Figure 5C). Aggregates of C. jejuni and E. coli and of C. jejuni and L. monocytogenes co-cultures were also larger and included more bacterial cells than for the aggregates of E. coli and L. monocytogenes co-cultures. Then, when all three of these bacteria were included in co-cultures together, they were closely aggregated, and organized such that the E. coli and L. monocytogenes cells were arranged on the inside of the aggregates, and the $C$. jejuni cells formed the edges of the aggregates (Figure 5G,H). In these co-cultures of all three bacteria, the $C$. jejuni cells were more elongated (Figure 5G,H) than in the $C$. jejuni mono-cultures (Figure 5A).
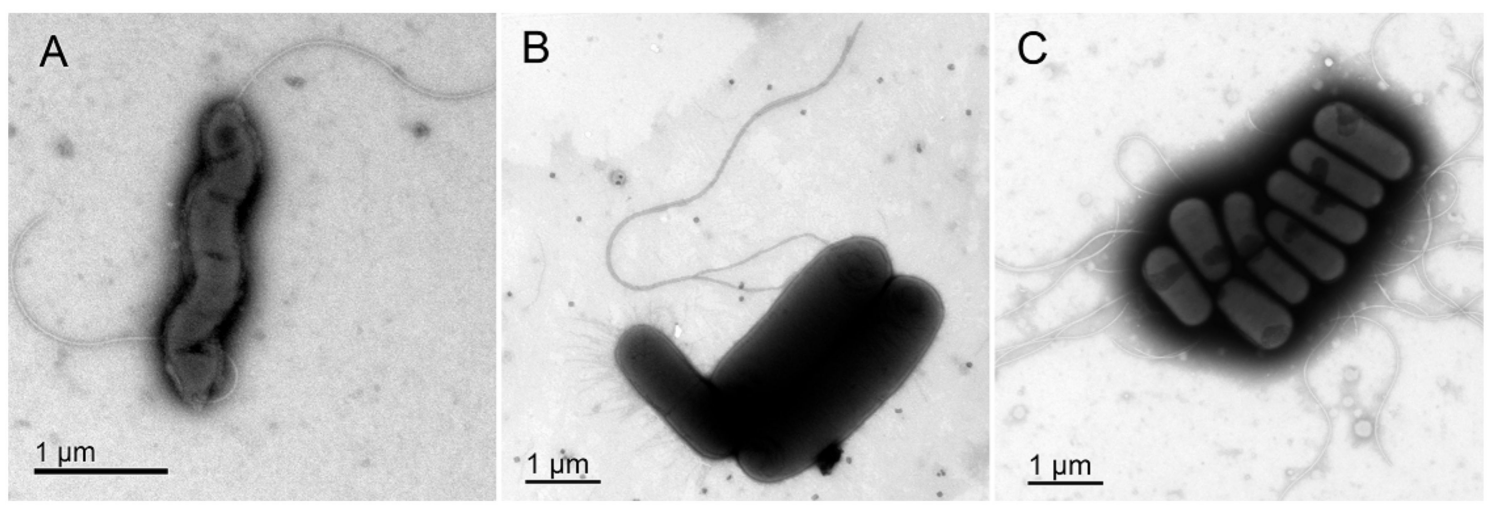

Figure 4. Representative transmission electron micrographs of the negatively stained control bacteria. (A) C. jejuni. (B) E. coli. (C) L. monocytogenes. Scale bars, as shown. 

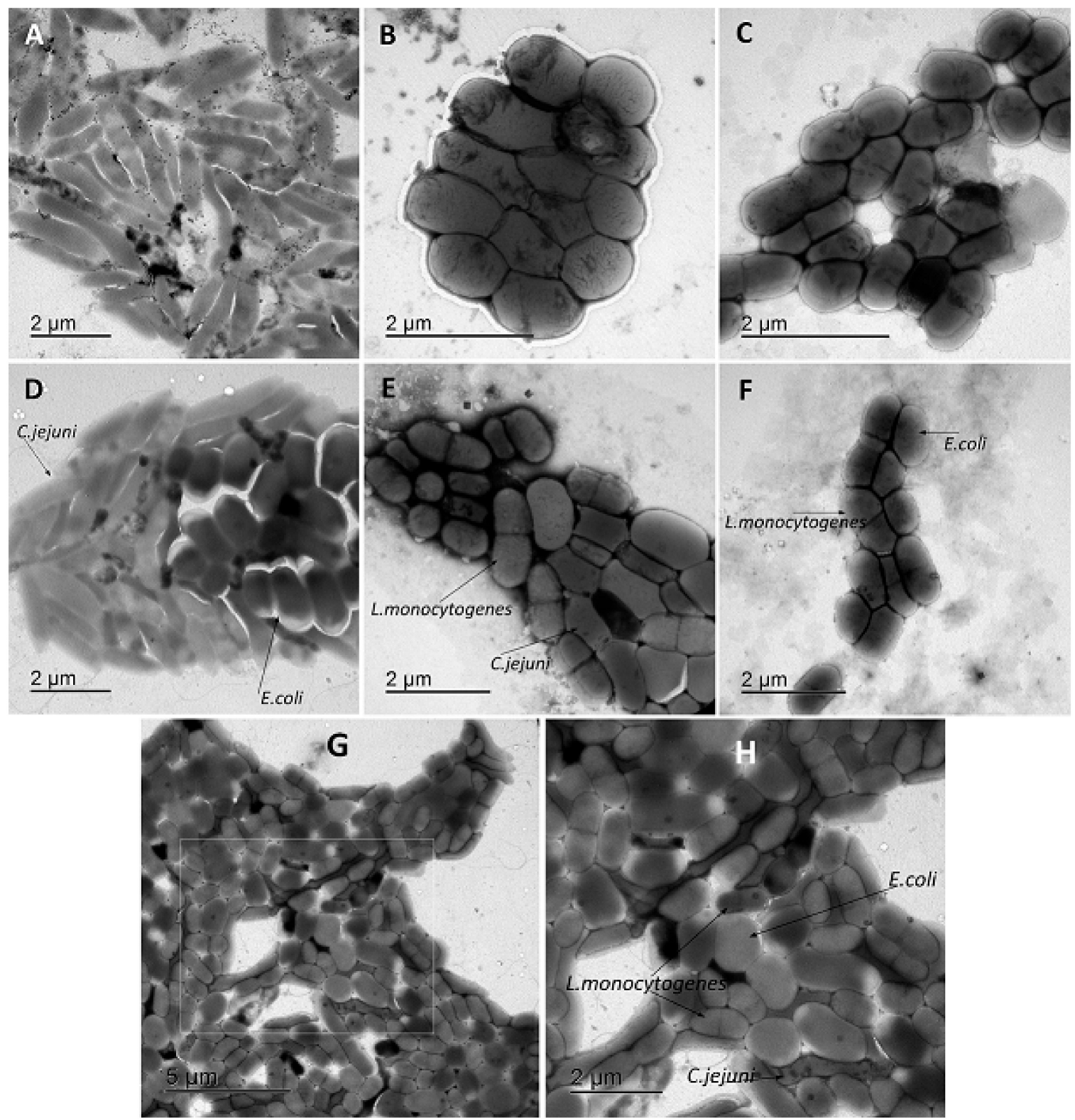

Figure 5. Representative transmission electron micrographs of the bacterial aggregation and co-aggregation. (A) C. jejuni. (B) E. coli. (C) L. monocytogenes. (D) Mixed culture of C. jejuni and E. coli. (E) Mixed culture of C. jejuni and L. monocytogenes. (F) Mixed culture of E. coli and L. monocytogenes. (G) Mixed culture of C. jejuni, E. coli and L. monocytogenes. (H) Enlargement of box shown in (G). Scale bars, as shown.

\section{Discussion}

Although there remain high levels of Campylobacter infections, these have not been brought under control and have instead showed significant increase over recent years [1,25]. At the same time, the mechanism by which C. jejuni causes human disease is still poorly understood [26]. As bacterial adhesion is important for biofilm formation, we investigated the modulation of $C$. jejuni adhesion in co-cultures of the foodborne pathogens L. monocytogenes and E. coli. We asked whether E. coli and L. monocytogenes can influence the levels of $C$. jejuni adherence to different surfaces, such as those of foods, hosts, or environments, which were here exemplified by the surfaces of polystyrene, human intestinal epithelial cells (Caco-2 cells) and A. castellanii amoebae. Adhesion to polystyrene was determined after $24 \mathrm{~h} \mathrm{[11]}$, and to Caco-2 cells and A. castellanii after $2 \mathrm{~h}$, to avoid the main bacterial 
internalization and the formation of amoebal cysts [24]. In our experiments, we confirmed that these were the optimal incubation times and therefore we consider that the results are comparable [5,22].

Adhesion of bacteria to abiotic surfaces is mediated by non-specific (e.g., hydrophobic) interactions [27], whereas their adhesion to living cells is accomplished through specific molecular mechanisms, such as those involving lectin, specific ligands, or adhesion $[3,9,11,28]$.

The adhesion of C. jejuni was similar to that previously observed [27], although Campylobacter biofilms, biomass, and ultrastructure differ between strains [29]. In the present study, the adhesion of C. jejuni to polystyrene was higher than seen for adhesion to the Caco-2 cells and A. castellanii. This attachment of $C$. jejuni cells to the biotic surfaces was lower because of the host-cell defences, such as the mucus layer that forms a barrier and can limit access of microbes to the epithelial cell surface, and the peristalsis that mechanically removes unattached bacteria $[2,26]$.

Lower adhesion to the eukaryotic cell host also directly influences the number of successfully internalized bacterial. Internalisation of C. jejuni in co-cultures with amoebae depends on type of amoeba and the bacterial viability [15]. Oloffson et al. showed that approximately $90 \%$ of viable $C$. jejuni cells were attached to $A$. polyphaga, with $10 \%$ in the intracellular vacuoles of these amoebae after $1 \mathrm{~h}$ of incubation [15]. Prolonged incubations (24-96 h) resulted in more than $80 \%$ of the C. jejuni inside these intracellular vacuoles. Vieira et al. described the contribution of a Campylobacter efflux pump to bacterial survival within amoebae [29]. In the present study with $A$. castellanii, $<0.01 \%$ of the viable C. jejuni cells were internalized after $2 \mathrm{~h}$ of incubation with $A$. castellanii. As for adhesion, the internalization of $C$. jejuni into the Caco-2 cells in the present study was also comparable to published data [28].

Additionally, strain differences and stress responses to environmental conditions such as temperature (i.e., $25^{\circ} \mathrm{C}, 37^{\circ} \mathrm{C}$ ) and oxygen concentration (i.e., aerobic, microaerophilic) can affect the C. jejuni interactions with $A$. castellanii, and consequently modulate C. jejuni viability, adhesion and internalisation [14]. C. jejuni is a microaerophilic organism that is sensitive to atmospheric oxygen, while variable oxygen concentrations will be encountered within cell lines and various hosts [2]. Thus, as expected, the adhesion of $\mathrm{C}$. jejuni at $25^{\circ} \mathrm{C}$ and $37^{\circ} \mathrm{C}$ and under the aerobic conditions of the present study was lower when compared to that of E. coli and L. monocytogenes, which showed higher adhesion regardless of the target surface used. This is in consistence with the well-studied formation of E. coli and L. monocytogenes mono-culture biofilms, where the initial adhesion occurs within a few seconds [30]. This thus contributes to their persistence on food-processing surfaces and the subsequent cross-contamination or re-contamination of food products [30].

For L. monocytogenes, Doyscher et al. showed that these bacteria can form 'backpacks' on the surface of $A$. castellanii within the first $10 \mathrm{~min}$ to $20 \mathrm{~min}$ of exposure, and then these amoebae start to phagocytose entire aggregates that are attached to their surface [31]. Then after approximately $6 \mathrm{~h}$, all of these backpacks are phagocytosed and the L. monocytogenes cells are digested in the food vacuoles of $A$. castellanii. We showed here that also after $2 \mathrm{~h}$ approximately $10^{4}$ and $10^{3} \mathrm{CFU} / \mathrm{mL}$ L. monocytogenes cells were intracellular in the A. castellanii when these L. monocytogenes were used as mono-cultures and as co-cultures with C. jejuni and E. coli, respectively. The lipopolysaccharides on the surface of Gram-negative bacteria have a major role in E. coli uptake by A. castellani [32]. The present study, a non-pathogenic E. coli strain was used (ATCC 11229), and these bacteria were not internalized by $A$. castellanii. It appears that $A$. castellanii represent a good model to study C. jejuni, E. coli, and L. monocytogenes adhesion under in vivo conditions.

Furthermore, we investigated whether E. coli and L. monocytogenes can influence C. jejuni adherence to the different surfaces. Interestingly, these data showed significantly enhanced C. jejuni adhesion to both the abiotic and biotic surfaces when in co-cultures with E. coli and L. monocytogenes, in comparison to the adhesion of $C$. jejuni mono-cultures. These data constitute an example of the $C$. jejuni survival strategy, and they highlight the modulation of adhesion in co-cultures that is potentially present in water, food products, and food production environments, and in the poultry gut and human digestive tract, with particular concern related to Campylobacter outbreaks. However, these pathways 
are compatible for other food-borne pathogenic bacteria as well, and the shared pathways lead to cross contamination. Studies of bacterial interactions are important, as co-infection with food-borne pathogens like E. coli or L. monocytogenes can promote C. jejuni colonization and infection, although $L$. monocytogenes may also reduce C. jejuni colonization [13]. Also, the species composition of biofilms in vivo can change by up to $40 \%$ every day with multispecies biofilms [18], where the levels of C. jejuni have been shown to be enhanced after $24 \mathrm{~h}$ when incubated with other bacteria at two initial inoculum densities [27]. Positive impacts on C. jejuni adhesion might be due to its increased growth or increased biomass, to its co-aggregation with other bacteria to form clusters that can deposit on the surfaces to initiate colonization, or to larger amounts of additional extracellular matrices of other species that can provide micro-niches in multispecies biofilms [32,33]. Additionally, the metabolic by-products of one organism might serve to support the growth of another, while the adhesion of one species might provide ligands that promote the attachment of others [34]. The reasons for the increased adhesion of C. jejuni might also relate to their survival characteristics, their ability to response to stress conditions, which include oxidative stress using $\mathrm{O}_{2}$ as an advantage for biofilm development, or their transition to more resistant cell forms [27,35]. Furthermore, the mechanism of $C$. jejuni biofilm formation might be a general response to adverse conditions that supports their high genetic diversity, which might contribute to longer term adaptation to varying environmental conditions, and the release of eDNA under biofilm conditions, which can promote the conditions that potentially serve for horizontal gene transfer [11,34]. Indeed, co-culture-enhanced C. jejuni adhesion can lead to increased resistance and survival of these fastidious and oxygen-sensitive Campylobacter in these environments, and under industrial conditions and during host interactions. The following disease is thus defined not only by the host-pathogen relationship, but also by a spectrum of host-microbe pathogenic mechanisms, microbe-microbe interactions, host immunity-mediated antimicrobial defences, and environmental factors [34].

As has been shown, several important foodborne pathogens have interspecies interactions when adhered or when in biofilms [17,27,32]. Furthermore, bacterial aggregation is an important mechanism for foodborne bacterial pathogen attachment to abiotic surfaces and initiation of micro-colony growth, and it represents the main type of cooperative interactions that facilitate co-adhesion of bacterial pairs to the surface [17,34]. In terms of co-aggregation, the succession of bacterial biofilms is tightly controlled by specific cell-surface-associated receptor-ligand interactions, and these often result in enhanced levels of multispecies biofilm formation [17]. In the present study, C. jejuni underwent significant aggregates after $24 \mathrm{~h}$, which indicated the potential mechanism of $C$. jejuni for synergistic interactions between different species during biofilm formation. All three investigated bacteria could be found simultaneously in food-producing animals affecting each other. The co-culturing of C. jejuni with E. coli and L. monocytogenes resulted in even higher co-aggregation when compared to $C$. jejuni as mono-cultures. Consequently, we can propose that both E. coli and L. monocytogenes can serve as pioneering attached bacteria that can be recognized and provide anchors for secondary bacterial colonizers. Additionally, the close contact that results from co-aggregation events facilitates cooperation between the different species, as reported previously $[17,36,37]$. Co-aggregation of specific secondary colonizers to already attached biofilms affects the organisation of oral multispecies biofilms [32,36,37], although this has not been confirmed for other bacteria. However, the representative TEM micrographs in the present study showed morphological changes of the bacteria tested as aggregates. In the aggregates and co-aggregates, the C. jejuni cells were elongated, with enhanced aggregates in co-cultures. Of particular interest, with all three of the bacteria in co-cultures, they formed specifically organized aggregates where $C$. jejuni formed the edges of the aggregates.

\section{Conclusions}

The data are of particular importance for risk assessment of Campylobacter in food. We have shown that studies of $C$. jejuni mono-culture adhesion can lead to misleading conclusions, as the presence of microflora in food and other environments can be decisive for the infective potential 
of $C$. jejuni. The present data indicate significant modulation of $C$. jejuni adhesion and suggest that bacteria that are commonly present in vivo within environments related to the food industry and in humans can facilitates and accelerate $C$. jejuni adhesion. These data suggest that, in partnership with other foodborne bacteria, $C$. jejuni present significantly higher risk than when in mono-culture because of this enhanced adhesion. Further investigations into $C$. jejuni adhesion properties and the complexity of these interactions within multispecies biofilms are therefore crucial for our understanding of $C$. jejuni adaptation, resistance, and virulence. This should allow for the modification of aspects within food processing environments to reduce microbial persistence, potentially through changed surfaces or the development of effective cleaning programmes, to consequently reduce Campylobacter and their infection transmission.

Author Contributions: A.K., I.G. and M.T.Ž. performed the experiments, analyzed data and wrote the paper. A.K., B.J. and D.V. designed and coordinated the study, and evaluated the performance and laboratory measurements. A.K., B.J., D.V. and M.A. contributed with interpretation of the results and helped drafting the manuscript. S.S.M. participated in drafting the manuscript. All authors have read and agreed to the published version of the manuscript.

Funding: The study was funded by the Slovenian Research Agency (Grant No. P4-0116 and J4-9299), and the University of Rijeka, Croatia (Grant No. 13.06.2.2.60 and 13.06.1.1.07).

Conflicts of Interest: The authors declare no conflict of interest.

\section{References}

1. Kaakoush, N.O.; Castaño-Rodríguez, N.; Mitchell, H.M.; Man, S.M. Global epidemiology of Campylobacter infection. Clin. Microbiol. Rev. 2015, 28, 687-720. [CrossRef]

2. Sulaeman, S.; Hernould, M.; Schaumann, A.; Coquet, L.; Bolla, J.M.; De, E.; Tresse, O. Enhanced adhesion of Campylobacter jejuni to abiotic surfaces is mediated by membrane proteins in oxygen-enriched conditions. PLoS ONE 2012, 7, e46402. [CrossRef]

3. Teh, A.H.T.; Lee, S.M.; Dykes, G.A. Does Campylobacter jejuni form biofilms in food-related environments? Appl. Environ. Microbiol. 2014, 80, 5154-5160. [CrossRef] [PubMed]

4. $\quad$ EFSA; ECDC. The European Union One Health 2018 Zoonoses Report. EFSA J. 2019, 17, e05926.

5. Šikić Pogačar, M.; Klančnik, A.; Bucar, F.; Langerholc, T.; Smole Možina, S. Alpinia katsumadai extracts inhibit adhesion and invasion of Campylobacter jejuni in animal and human foetal small intestine. Phytother. Res. 2015, 29, 1585-1589. [CrossRef] [PubMed]

6. Klančnik, A.; Šikić Pogačar, M.; Trošt, K.; Tušek Žnidarič, M.; Mozetič Vodopivec, B.; Smole Možina, S. Anti-Campylobacter activity of resveratrol and an extract from waste Pinot noir grape skins and seeds, and resista nce of $C$. jejuni planktonic and biofilm cells mediated via the CmeABC efflux pump. J. Appl. Microbiol. 2017, 122, 65-77.

7. ŠSikić Pogačar, M.; Rubeša Mihaljević, R.; Klančnik, A.; Brumini, G.; Abram, M.; Smole Možina, S. Survival of stress exposed Campylobacter jejuni in the murine macrophage J774 cell line. Int. J. Food Microbiol. 2009, 129, 68-73. [CrossRef]

8. Klančnik, A.; Guzej, B.; Jamnik, P.; Vučković, D.; Abram, M.; Smole Možina, S. Stress response and pathogenic potential of Campylobacter jejuni cells exposed to starvation. Res. Microbiol. 2009, 160, 345-352. [CrossRef]

9. Rubinchik, S.; Seddon, A.M.; Karlyshev, A.V. A negative effect of Campylobacter capsule on bacterial interaction with an analogue of a host cell receptor. BMC Microbiol. 2014, 14, 141. [CrossRef]

10. Fields, J.A.; Li, J.; Gulbronson, C.J.; Hendrixson, D.R.; Thompson, S.A. Campylobacter jejuni CsrA regulates metabolic and virulence associated proteins and is necessary for mouse colonization. PLoS ONE 2016, 11, e0156932. [CrossRef]

11. Svensson, S.L.; Pryjma, M.; Gaynor, E.C. Flagella-mediated adhesion and extracellular DNA release contribute to biofilm formation and stress tolerance of Campylobacter jejuni. PLoS ONE 2014, 9, e106063. [CrossRef] [PubMed]

12. Axelsson-Olsson, D.; Olofsson, J.; Svensson, L.; Griekspoor, P.; Waldenström, J.; Ellström, P.; Olsen, B. Amoebae and algae can prolong the survival of Campylobacter species in co-culture. Exp. Parasitol. 2010, 126, 59-64. [CrossRef] 
13. Wang, G.; He, Y.; Jin, X.; Zhou, Y.; Chen, X.; Zhao, J.; Zhang, H.; Chen, W. The effect of co-infection of food-borne pathogenic bacteria on the progression of Campylobacter jejuni infection in mice. Front. Microbiol. 2018, 9, 1977. [CrossRef] [PubMed]

14. Bare, J.; Sabbe, K.; Huws, S.; Vercauteren, D.; Braeckmans, K.; van Gremberghe, I.; Houf, K. Influence of temperature, oxygen and bacterial strain identity on the association of Campylobacter jejuni with Acanthamoeba castellanii. FEMS Microbiol. Ecol. 2010, 74, 371-381. [CrossRef]

15. Olofsson, J.; Olsson, D.A.; Brudin, L.; Olsen, B.; Ellstro, P. Campylobacter jejuni actively invades the amoeba Acanthamoeba polyphaga and survives within non digestive vacuoles. PLoS ONE 2013, 8, e78873. [CrossRef] [PubMed]

16. Brown, M.R.; Barker, J. Unexplored reservoirs of pathogenic bacteria: Protozoa and biofilms. Trends Microbiol. 1999, 7, 46-50. [CrossRef]

17. Giaouris, E.; Heir, E.; Desvaux, M.; Hébraud, M.; Møretrø, T.; Langsrud, S.; Simões, M. Intra- and inter-species interactions within biofilms of important foodborne bacterial pathogens. Front. Microbiol. 2015, 6, 1-26. [CrossRef] [PubMed]

18. Reuter, M.; Mallett, A.; Pearson, B.M.; van Vliet, A.H.M. Biofilm formation by Campylobacter jejuni is increased under aerobic conditions. Appl. Environ. Microbiol. 2010, 76, 2122-2128. [CrossRef]

19. Lekshmi, M.; Ammini, P.; Kumar, S.; Varela, M.F. The food production environment and the development of antimicrobial resistance in human pathogens of animal origin. Microorganisms 2017, 5, 11. [CrossRef]

20. Szymanski, C.M.; Gaynor, E.C. How a sugary bug gets through the day. Recent developments in understanding fundamental processes impacting Campylobacter jejuni pathogenesis. Gut Microbes 2012, 3, 135-144. [CrossRef]

21. Rubeša Mihaljević, R.; Šikić, M.; Klančnik, A.; Brumini, G.; Smole Možina, S.; Abram, M. Environmental stress factors affecting survival and virulence of Campylobacter jejuni. Microb. Pathogen. 2007, 43, 120-125. [CrossRef] [PubMed]

22. Klančnik, A.; Gobin, I.; Vučković, D.; Smole Možina, S.; Abram, M.; Jeršek, B. Reduced contamination and infection via inhibition of adhesion of foodborne bacteria to abiotic polystyrene and biotic amoeba surfaces. Int. J. Food Sci. Technol. 2018, 53, 1013-1020. [CrossRef]

23. Kos, B.; Susković, J.; Vuković, S.; Simpraga, M.; Frece, J.; Matosić, S. Adhesion and aggregation ability of probiotic strain Lactobacillus acidophilus. J. Appl. Microbiol. 2003, 94, 981-987. [CrossRef] [PubMed]

24. Akya, A.; Pointon, A.; Thomas, C. Viability of Listeria monocytogenes in co-culture with Acanthamoeba spp. FEMS Microbiol. Ecol. 2009, 70, 20-29. [CrossRef]

25. EFSA, European Food Safety Authority. The European Union summary report on trends and sources of zoonoses, zoonotic agents and food-borne outbreaks in 2015. EFSA J. 2016, 14, 4634.

26. Bolton, D.J. Campylobacter virulence and survival factors. Food Microbiol. 2015, 48, 99-108. [CrossRef]

27. Sanders, S.Q.; Frank, J.F.; Arnold, J.W. Temperature and nutrient effects on Campylobacter jejuni attachment on multispecies biofilms on stainless steel. J. Food Prot. 2008, 71, 271-278. [CrossRef]

28. Backert, S.; Hofreuter, D. Molecular methods to investigate adhesion, transmigration, invasion and intracellular survival of the foodborne pathogen Campylobacter jejuni. J. Microbiol. Methods 2013, 95, 8-23. [CrossRef]

29. Vieira, A.; Ramesh, A.; Seddon, A.M.; Karlyshev, A.V. CmeABC multidrug efflux pump contributes to antibiotic resistance and promotes Campylobacter jejuni survival and multiplication in Acanthamoeba polyphaga. Appl. Environm. Microbiol. 2017, 83, e01600-17. [CrossRef]

30. Pilchová, T.; Hernould, M.; Prévost, H.; Demnerová, K.; Pazlarová, J.; Tresse, O. Influence of food processing environments on structure initiation of static biofilm of Listeria monocytogenes. Food Control 2014, 35, 366-372. [CrossRef]

31. Doyscher, D.; Fieseler, L.; Dons, L.; Loessner, M.J.; Schuppler, M. Acanthamoeba feature a unique backpacking strategy to trap and feed on Listeria monocytogenes and other motile bacteria. Environ. Microbiol. 2013, 15, 433-446. [CrossRef] [PubMed]

32. Rickard, A.H.; Gilbert, P.; High, N.J.; Kolenbrander, P.E.; Handley, P.S. Bacterial co-aggregation: an integral process in the development of multi-species biofilms. Trends Microbiol. 2003, 11, 94-100. [CrossRef]

33. Arnold, J.W.; Spacht, D.; Koudelka, G.B. Determinants that govern the recognition and uptake of Escherichia coli O157:H7 by Acanthamoeba castellanii. Cell Microbiol. 2016, 18, 1459-1470. [CrossRef] [PubMed] 
34. Pascoe, S.; Locantore, N.; Dransfield, M.T.; Barnes, N.C.; Pavord, I.D. Blood eosinophil counts, exacerbations, and response to the addition of inhaled fluticasone furoate to vilanterol in patients with chronic obstructive pulmonary disease: a secondary analysis of data from two parallel randomised controlled trials. Lancet Respir. Med. 2015, 3, 435-442. [CrossRef]

35. Klančnik, A.; Vučković, D.; Jamnik, P.; Abram, M.; Smole Možina, S. Stress response and virulence of heat stressed Campylobacter jejuni. Microbes Environ. 2014, 29, 338-3345. [CrossRef]

36. Guo, A.; Xu, Y.; Mowery, J.; Nagy, A.; Bauchan, G.; Nou, X. Ralstonia insidiosa induces cell aggregation of Listeria monocytogenes. Food Control 2016, 67, 303-309. [CrossRef]

37. Liu, N.T.; Bauchan, G.R.; Franceour, C.B.; Shelton, D.R.; Lo, Y.M.; Nou, X. Ralstonia insidiosa serves as bridges in biofilm formation by foodborne pathogens Listeria monocytogenes, Salmonella enterica, and enterohemorrhagic Escherichia coli. Food Control 2016, 65, 14e20. [CrossRef]

(C) 2020 by the authors. Licensee MDPI, Basel, Switzerland. This article is an open access article distributed under the terms and conditions of the Creative Commons Attribution (CC BY) license (http://creativecommons.org/licenses/by/4.0/). 